\title{
Chinese Calligraphic Handwriting (CCH): Treatment of Clinical Symptoms of Children with Autism
}

\author{
Henry SR Kao ${ }^{1 *}$, Hu Bin ${ }^{2}$, Yushi Jiang ${ }^{3}$ and Tin Tin Kao ${ }^{1}$ \\ ${ }^{1}$ Department of Psychology University of Hong Kong, China \\ ${ }^{2}$ Haidian Special School for Mental Retardation, Beijing \\ ${ }^{3}$ Yishuge gGmbH, Berlin \\ *Corresponding author: Henry SR Kao, Department of Psychology University of Hong Kong, China
}

\begin{abstract}
Background: Chinese calligraphy handwriting (CCH) enhances one's cognitive, emotional and physiological functions and mental health conditions. Its applications have resulted in behavioral change, mental relaxation as well as improvements in the clinical conditions of the children with, Autism, ADHD and PTSD, showing positive and significant results Kao [1].

Objectives: We tested the treatment effects of CCH training on reducing autistic children's behavioural changes and clinical symptoms exhibited in schools and at home.

Method: The experiment included 30 autistic children whose behaviour activities and clinical symptoms were measured by the Childhood Autism Rating Scale (CARS) and the Infant Behavioral Summarized Evaluation (IBSE). The CCH writing task involved 40 minutes a day, five days a week, for a total of 4 consecutive weeks. The assessment took place five times: once before the experiment, and once per week during the four week's training period.

Results: There were post-CCH training improvement in the four dimensions of Socialization, Communication, Living Environment and Attention/Consciousness, and the Total Score at the 0.01 level of significance of the IBSE assessment. Similarly, we found post-CCH training improvements for the Total Score and the 3 behavior dimensions of Interpersonal Relations, Verbal Communication and Strange Movements, and Rituals of the CARS subscales also all at 0.01 level of significance.

Discussion: The findings of this experiment were overwhelming: in most aspects of the autistic disorders measured by the ISBE (5/7) and CARS (4/5), there were highly significant changes and improvements as a result of the CCH training. These outcomes have important theoretical and practical implications.
\end{abstract}

\section{Introduction}

Autism, or autism spectrum disorder (ASD), refers to a broad range of conditions characterized by challenges with social skills, repetitive behaviors, speech and nonverbal communication. Autism prevalence in the West is approximately $1 \%$ of school age children. Autism prevalence in China has been reported recently as similar to that in the West, also at $1 \%$ Sun X, Allison C, Wei L, Matthews FE, Auyeung B, Wu YY, Griffiths S, Zhang J, Baron-Cohen S, Brayne C.; 2019). Behaviour therapies in general are effective in helping to relieve social and communicative disorders associated with autism. Along this line of development, new and alternative models of treatment continue to be important and need to be explored. Chinese calligraphic handwriting ( $\mathrm{CCH})$, or the brush writing of Chinese characters, is a motor production of visual geometric patterns of character structure. It involves a 3-D motor act aided by the application of a soft and pliable brush tip. These visual patterns usually follow one of several conventional styles of Chinese calligraphy.

Studies on CCH have established its effects on visual alertness, cognitive activation, emotional stability as well as physiological quiescence and relaxation Kao [2,3]. These findings have formed the basis of recent investigations into the application of $\mathrm{CCH}$ as a new model of treatment on certain behavioral and clinical disorders Kao [4]. In the areas of childhood and related disorders, we have studied attention-deficit/hyperactivity (ADHD) Chen CJ \& Wang SQ et al. [4,5], Autism Bin Hu et al. [5], mental retardation Kao HSR et al. [6] PTSD Zhu ZH et al. [7]. These preliminary findings have provided 
a sound scientific basis to investigate the treatment effects of $\mathrm{CCH}$ in children suffering from other behavioural or developmental disorders such as some clinical symptoms in Autism. We aimed in the present study to test the efficacy of the $\mathrm{CCH}$ training as an effective treatment in the improvement of interpersonal relations, social behaviour, and speech communication that were associated with children with autism. In addition, it was designed also to examine change and likely reduction of clinical symptoms in children with autism. Two experiments were conducted.

\section{Method}

\section{Participants}

A total of 30 participants (23 males and 7 females, aged 1015 years old) meeting our inclusion criteria were recruited. They were clinically diagnosed and referred by district authorities to the special school. They had an IQ score between 24 and 66 and a mean of 48. Two of the children suffered from moderate and four suffered from severe stereotypical behaviors of autism such asvarying degrees of lack of social interactions. Four showed signs of refusal of normal social interaction, two had little or no social interaction with others, and two avoided social activities. Cognitively, three of them had acceptable level of cognitive aptitude while the other three had varied ability in abstract reasoning, rote memory and general reasoning ranging from poor to average. As to linguistic disorders, four suffered from echolalia, three also had delayed echolalia, and two showed no signs of speech initiation. One child also had symptoms of self-talk and the last one was aphasic with no signs of speech communication. None of the children had any prior experience with Chinese calligraphy before the experiment.

\section{Instruments}

The Chinese versions of the Childhood Autism Rating Scale (CARS) Schopler E et al. [8] and the Infant Behavior Summarized Evaluation (IBSE) Adrien JL et al. [9] were used and filled out by the teacher of the class before and after the CCH training schedule. Behavior changes between the two assessments for both CARS and IBSE were the basis of the impact of $\mathrm{CCH}$ on these autistic children. The IBSE has 33 items falling into 6 categories of children's behavior, including Socialization, Communication, Situational Adjustment, Autonomy, Emotions and Instinctual Response, and Attention and Perception. This instrument measured changes in basically the interpersonal activities as well as socialization behavior in these children.

The CARS scale has 15 items and evaluates various aspects of autistic behaviors in terms of the child's general adaptive ability to the immediate environment. The behaviors assessed include Interpersonal Relations, Imitation, Affective Response, Strange Movements and Rituals, Resistance to Changes in the Environment, Shallow Sensory Response, Anxiety Response, Verbal and NonVerbal Response, Intellectual Functions, etc., as well as a Total Rating.

\section{Procedure}

One week before the experiment, all 30 participants were assessed on the CARS and IBSE scales as the pre-test he $\mathrm{CCH}$ training schedule involved a daily writing session of 40 minutes, 5 days a week and consecutive 4 weeks. Each day, the class teacher of the autistic children would bring them to the CCH Training Lab at a regular time to be received by the $\mathrm{CCH}$ therapist. The therapist would seat each child to his or her assigned seat, while at the same time engaging in verbal and gestural instructions to make the writing session comfortable and friendly. She would show and tell the child the names of various instruments, such as brush, ink and paper and asking them to repeat the items. This would be followed by instruction on pen use, brush control, explanation of the meaning, sequence, structure of the characters to be practiced. The children were also asked to read out each character loudly together with the therapist in order to learn the character as well as to stabilize their states of anxiety and uneasiness of the time.

There were 4 common and familiar characters to be written in the Regular style of Chinese calligraphy with the possibility of repetition before time ran out. The mode of brush writing was tracing for the first 2 weeks, during which the child wrote with sample characters placed directly under a thin sheet of rice paper. It was copying for the last 2 weeks, in which the child wrote by copying the same sample characters placed away from his writing paper. At the end of each $\mathrm{CCH}$ session, the child was required to return the written work together with the sample characters to the therapist. The children were then escorted and returned to their respective regular classes by the therapist.

\section{Results}

Table 1: Baseline measures by gender group.

\begin{tabular}{|c|c|c|c|}
\hline Sex (mean (SD)) & Male & Female & P-value $^{*}$ \\
\hline IBSE Total (pretest) & $1.86(.59)$ & $1.80(.49)$ & 0.825 \\
\hline Socialization & $2.30(.73)$ & $2.57(.40)$ & 0.364 \\
\hline Communication & $2.15(.69)$ & $2.31(.55)$ & 0.567 \\
\hline Living environment & $2.04(.71)$ & $2.02(.72)$ & 0.968 \\
\hline Autonomy & $1.44(.69)$ & $1.00(.40)$ & 0.121 \\
\hline Emotional and instinctive & $1.59(.93)$ & $1.57(1.08)$ & 0.971 \\
\hline response & $1.63(.73)$ & $1.34(.94)$ & 0.394 \\
\hline CAttention/consciousness & $2.91(0.49)$ & $2.68(0.43)$ & 0.282 \\
\hline Interpersonal relations & $3.07(.49)$ & $2.90(.62)$ & 0.481 \\
\hline Verbal communication & $2.70(.69)$ & $2.31(.60)$ & 0.184 \\
\hline Strange movements and & $2.95(.52)$ & $2.83(.74)$ & 0.636 \\
\hline
\end{tabular}


The gender and clinical characteristics of participants at the baseline showed no statistically significant differences (Table1). There was a significant improvement in the pre-post comparison for CARS total scores $(\mathrm{F}(1,27)=97.881, \mathrm{P}=0.000$,effect size 0.784$)$. None of the IBSE and CARS Total and subscale pre-post scores with gender group have significant interaction effects, except for Autonomy of IBSE $(F(1,28)=8.144, P=0.008$, Effect size 0.225$)$ see
Table 1 \& Figure 1 . This outcome might have been caused by the female subjects' small size $(\mathrm{N}=7)$ being too small to reflect a stable pre-post statistic data base. Figure 1 gives detailed comparison of all children's IBSE ratings before and after the $\mathrm{CCH}$ training schedule. These findings as a whole show a significant post-training improvement in the children's overall adjustments in the school environment.

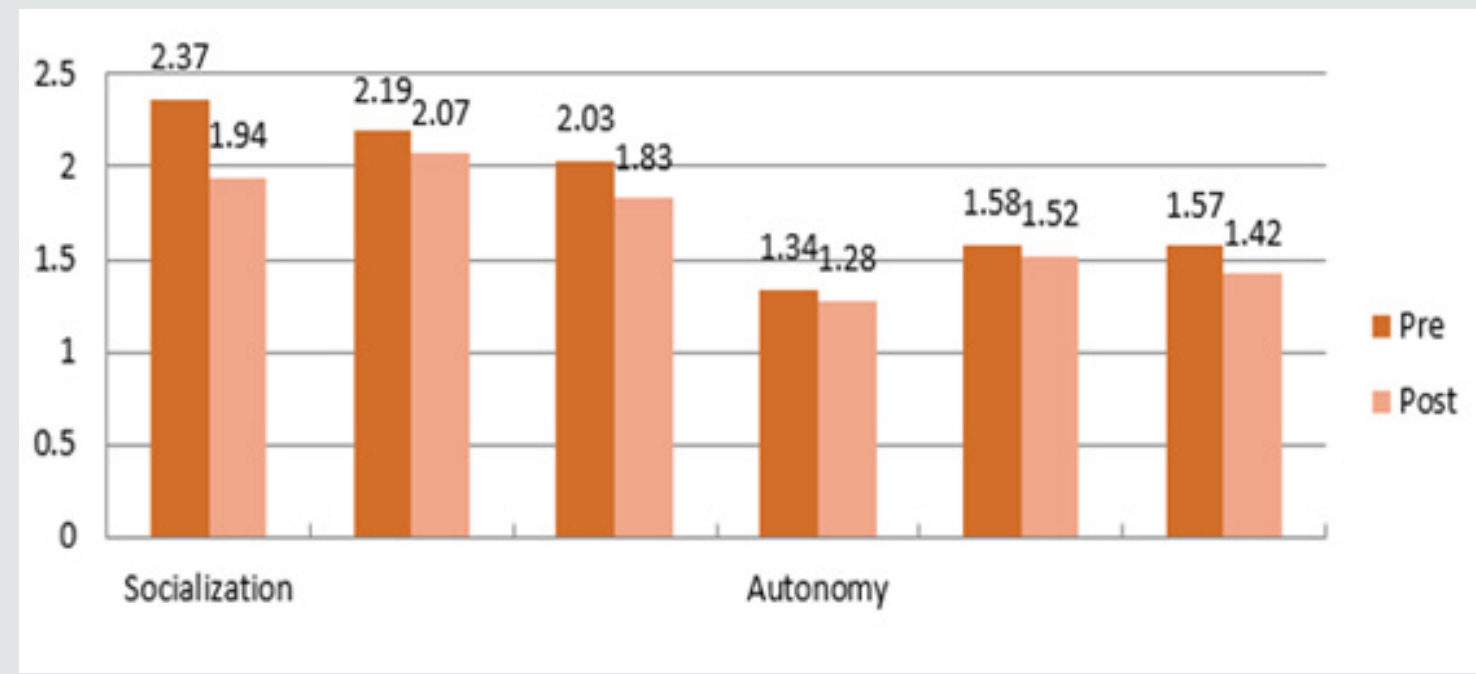

Figure 1: A graphic comparison in IBSE rating before and after the 4-week $\mathrm{CCH}$ practice schedule.

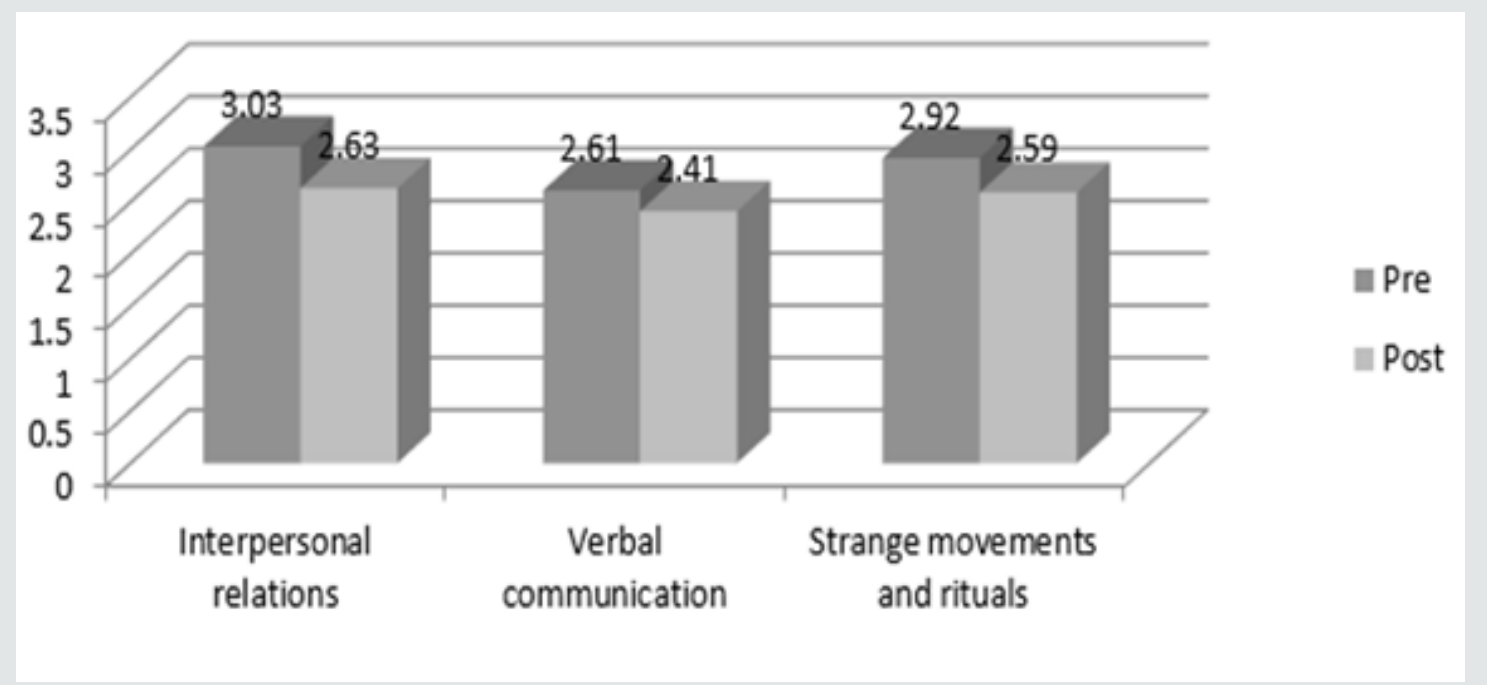

Figure 2: A graphic breakdown in CARS rating before and after the 4-week $\mathrm{CCH}$ practice schedule.

As for specific changes in patterns of behavior of the entire sample of autistic children due to the $\mathrm{CCH}$ practice, (Figure 2) confirms our original prediction. In the 6 dimensions of autistic behavior symptoms measured by the IBSE, the results had shown a post-training improvement. All 4 dimensions of Socialization
( $\mathrm{F}=15.994)$, Communication $(\mathrm{F}=9.909)$, Living Environment $(\mathrm{F}=6.78)$, and Attention/Consciousness $(\mathrm{F}=26.395)$ are significant at the 0.01 level.

Figure 2 showed a graphic breakdown of these individual changes in the CARS ratings before and after the 4-week $\mathrm{CCH}$ 
training schedule. The Total Score and the 3 behavior dimensions of Interpersonal Relations, Verbal Communication and Strange Movements and Rituals showed a post- $\mathrm{CCH}$ training improvement, all at 0.01 level of significance. These results further corroborate those obtained through the IBSE assessment of the same group of autistic children (Figure 2).

\section{Discussion}

The findings of this experiment are overwhelming. In every aspect of the behavioral disorders of autism investigated, there is a significant change and improvement after the 4-week CCH training schedule. The changes in attention and perception are especially noteworthy. It was previously established that attention plays an important role in affecting the speech communication, social interaction, and interpersonal relations of the autistic children Courchesne E et al. [10]. The present experiment has shown a confirmatory $\mathrm{CCH}$ effect on perceptual and attention-consciousness enhancements in these children, which are consistent with our previous positive CCH findings associated with visual and auditory attention in the children with mild mental retardation Kao HSR et al. [6], as well as with selective attention and sustained attention in children with hyperactivity Chen CJ et al. [4].

Moreover, the improved post-CCH behaviors in Communication, Socialization and Interpersonal Relations found in the present experiment are in line with research by Courchesne E et al. [10], but some more varied and enriched activities have been identified from our present investigation. All the findings from above sources are now made clear, reinforced and corroborated by the newly published ground- breaking discoveries on CCH's fundamental roles, through its long-term practice, in facilitating and improving the practitioner's specific aspects of executive functions as well as strengthening their neural networks in related brain regions. Chen W et al. [11]; More specifically, the latest fMRI studies have further established the CCH's capability of improving the practitioner's selective attention and divided attention through long-term calligraphic training Chen $\mathrm{W}$ et al. [12]. These imaging studies have provided convincing evidence over the bio-behavioral modification to aspects of the practitioner's perception and attention, as well as his brain structure. This significance enriches our understanding of the improvements regarding clinical and behavioral symptoms on childhood autism investigated in the present study.

The usual difficulties commonly experienced by autistic children such as contact initiation and interactive communication, which are also found to improve after the $\mathrm{CCH}$ training, are related to their adaptive inability to the social environments in the schools (Table 2). It seems reasonable that CCH training might be one model of treatment that facilitates positive changes of adaptive behaviors of the autism children. These changes are consistent with and at the heart of the therapeutic effects of the $\mathrm{CCH}$ practice for general health as well as for many aspects of the practitioner's perception, cognition, emotion and physiological changes that are associated with long-term practice of the seasoned practitioners Kao HSR \& Gerlach EK \& Kao HSR et al. [13-15]. These present findings are encouraging and have important theoretical and clinical implications especially with respect to developing $\mathrm{CCH}$ as a new model for effective therapeutic intervention of childhood disorders.

Table 2: Repeated-measures analysis of variance on significant IBSE and CARS total and subscale scores.

\begin{tabular}{|c|c|c|c|c|}
\hline Effects & $\boldsymbol{F}$ & df & P-value & Effect size \\
\hline \multicolumn{5}{|c|}{ IBSE Total(pretest) } \\
\hline Pre-post & 21.318 & 1,28 & 0 & 0.432 \\
\hline Pre-post x gender & 1.077 & 1,28 & 0.308 & 0.037 \\
\hline \multicolumn{5}{|l|}{ Socialization } \\
\hline Pre-post & 15.994 & 1,28 & 0 & 0.364 \\
\hline Pre-post x gender & 3.838 & 1,28 & 0.06 & 0.121 \\
\hline \multicolumn{5}{|l|}{ Communication } \\
\hline Pre-post & 9.909 & 1,28 & 0.004 & 0.261 \\
\hline Pre-post x gender & 0.24 & 1,28 & 0.628 & 0.009 \\
\hline \multicolumn{5}{|l|}{ Living Environment } \\
\hline Pre-post & 9.809 & 1,28 & 0.004 & 0.259 \\
\hline Pre-post x gender & 0.133 & 1,28 & 0.718 & 0.005 \\
\hline \multicolumn{5}{|l|}{ Autonomy } \\
\hline Pre-post & 0.017 & 1,28 & 0.897 & 0.001 \\
\hline Pre-post x gender & 8.144 & 1,28 & 0.008 & 0.225 \\
\hline \multicolumn{5}{|c|}{ Emotional and instinctive response } \\
\hline Pre-post & 2.585 & 1,28 & 0.119 & 0.085 \\
\hline Pre-post x gender & 0.24 & 1,28 & 0.628 & 0.009 \\
\hline \multicolumn{5}{|l|}{$\begin{array}{l}\text { Attention/Con- } \\
\text { sciousness }\end{array}$} \\
\hline Pre-post & 26.395 & 1,28 & 0 & 0.485 \\
\hline Pre-post x gender & 0.285 & 1,28 & 0.597 & 0.01 \\
\hline \multicolumn{5}{|l|}{ CARS Total (pretest) } \\
\hline Pre-post & 97.881 & 1,28 & 0 & 0.784 \\
\hline Pre-post x gender & 0.171 & 1,28 & 0.682 & 0.006 \\
\hline \multicolumn{5}{|c|}{ Interpersonal relations } \\
\hline Pre-post & 52.252 & 1,28 & 0 & 0.652 \\
\hline Pre-post x gender & 0.027 & 1,28 & 0.872 & 0.002 \\
\hline \multicolumn{5}{|l|}{$\begin{array}{l}\text { Verbal communi- } \\
\text { cation }\end{array}$} \\
\hline Pre-post & 24.391 & 1,27 & 0 & 0.475 \\
\hline Pre-post x gender & 0.351 & 1,27 & 0.558 & 0.013 \\
\hline \multicolumn{5}{|c|}{ Strange movements and rituals } \\
\hline Pre-post & 39.933 & 1,28 & 0 & 0.588 \\
\hline Pre-post x gender & 0.014 & 1,28 & 0.908 & 0 \\
\hline
\end{tabular}


Our CCH treatment becomes especially significant in light of the World Health Organization's (WHO) recent review of evidence on the impact of the arts on both mental and physical health Fancourt D et al. [16]. The WHO's European branch, in a groundbreaking report, looked at 900 publications, including reviews covering 3,000 further studies, from January 2000 to May 2019. A month of calligraphy training was shown to reduce stress in children who survived the 2008 China earthquakes. It also lessened hyperarousal, a side effect of PTSD which causes angry outbursts, panic attacks or anxiety that was conducted by our team Zhu ZH et al. [17]. We are very pleased with the WHO's praise and recognition of our work on CCH intervention and rehabilitation with the PTSD children.

\section{Acknowledgment}

We would like to thank the following persons for helpful assistance at the varying stages of this research: Stewart P.W. Lam, University of Hong Kong; Lin Zhu, Remin University of China; Ivy C.Y. Liu, Fujen Catholic University.

\section{References}

1. Kao HSR (2000) Chinese Calligraphic Therapy. University of Hong Kong Press, Hong Kong, China pp: 1-489.

2. Kao HSR, Lam PW, Robinson L, Yen NH (1989) Psychophysiological changes associated with Chinese calligraphy. In: R Plamondon, Suen CY, Simner ML (Eds.), Computer recognition and human production of handwriting, Singapore: World Scientific, Singapore, pp: 349-381.

3. Kao HSR (2006) Chinese calligraphic handwriting (CCH) a science for health and behavioural therapy. International Journal of Psychology 41(4): 282-286.

4. Chen CJ, Kao HSR (2000) Attentional Effects of Chinese Brush Handwriting on School Children. In HSR Kao. Chinese Calligraphic Therapy, Hong Kong University Press, China, pp: 93-101.

5. Bin Hu, Ying L, Kao HSR, Wang SQ (2006) Chinese calligraphic treatment of children with autism. International Journal of Behavioural Medicine 13: 238.

6. Kao HSR, Lai MF (2000) Effects of Chinese Brush Handwriting on the Visuo-auditory attention of Children with Mild Mental Retardation. In:
HSR Kao Chinese Calligraphic Therapy. Hong Kong University Press, China, Pp: 345-356.

7. Zhu ZH, Wang R, Kao HSR, Zong Y, Liu ZK, et al. (2014) Effect of calligraphy training on hyperarousal symptoms for childhood survivors of the 2008 China earthquakes. Neuropsychiatr Dis Treat 10: 977-985.

8. Schopler E, Reichler RJ, DeVellis RF, Kock K (1980) Toward objective classification of childhood autism: Childhood Autism Rating Scale (CARS). J Autism Dev Disord 10(1): 91-103.

9. Adrien JL, Bartheleny C, Perrot A, Roux S, Lenoir O, et al. (1992) Validity and reliability of the Infant Behavioural Summarized Evaluation (IBSE); a rating scale for the assessment of young children with autism and developemental disorders. Journal of Autism and Developmental Disorders 22(3): 375-394.

10. Courchesne E, Yeung-Courchesne R, Press GA, Hesselink JR, Jernigan TL (1988) Hypoplasia of cerebellar vermal lobules VI and VII in autism. N Engl J Med 318(21): 1349-1354.

11. Chen W, He Y, Gao Y, Zhang CP, Chen CS, et al. (2017) Long-Term Experience of Chinese Calligraphic Handwriting Is Associated with Better Executive Functions and Stronger Resting-State Functional Connectivity in Related Brain Regions 12(1) doi: ARTN e0170660 doi: 10.1371/ journal. pone.0170660. PubMed PMID: WOS:000396211400049. PMID: 28129407.

12. Chen W, Chen C, Yang P, Bi S, Liu J, Xia M, et al. (2019) Long-term Chinese calligraphic handwriting reshapes the posterior cingulate cortex: A VBM study. PLoS ONE 14(4): e0214917.

13. Kao HSR (2000) Chinese Calligraphic Therapy. University of Hong Kong Press, Hong Kong, China, pp: 417-425.

14. Gerlach EK (1993) Autism treatments guide. Or: Four Leaf Press, China.

15. Kao HSR, Hu B, Wang SQ (2006) Chinese calligraphic treatment of children with attention-deficit hyperactivity disorders (ADHD). International Journal of Behavioural Medicine 13S: 279.

16. Fancourt D, Finn S (2019) What is the evidence on the role of the arts in improving health and well-being? A scoping review. Copenhagen: WHO Regional Office for Europe; (Health Evidence Network (HEN) synthesis report 67), Europe.

17. Zhu ZH, Wang R, Kao HSR, Zong Y, Liu ZK, et al. (2014) Effect of calligraphy training on hyperarousal symptoms for childhood survivors of the 2008 China earthquakes. Neuropsychiatr Dis Treat 10: 977-985.

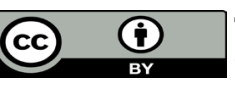

This work is licensed under Creative Commons Attribution 4.0 License

To Submit Your Article Click Here: Submit Article
DOI: $10.32474 /$ OAJCAM.2019.01.000126

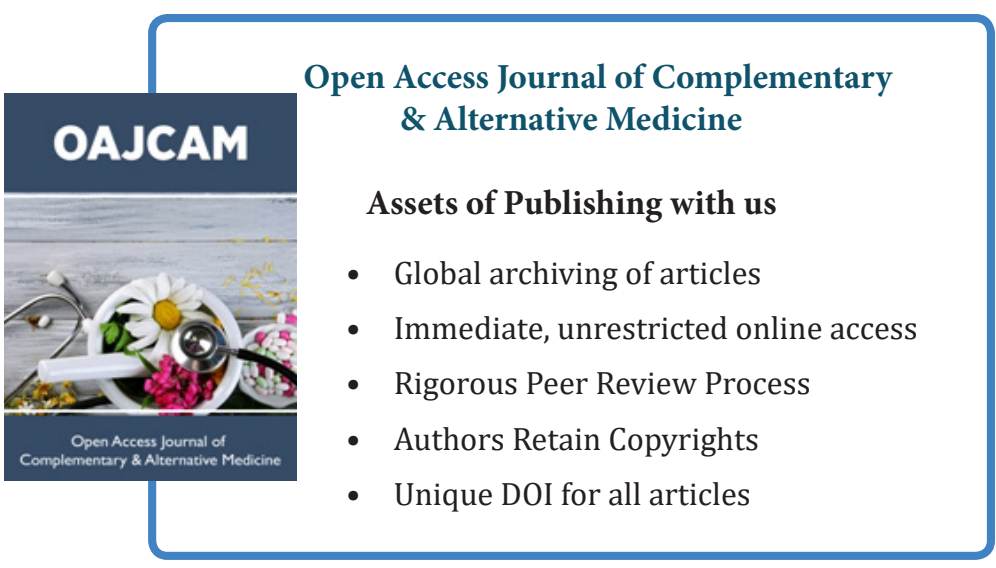

